\title{
Diet Rich in Plant Protein May Prevent Type 2 Diabetes ${ }^{+}$
}

\author{
Mauro Lombardo 1, Chiara Bellia ${ }^{2}$, Cristian Moletto ${ }^{1}$, Giovanni Aulisa ${ }^{1}$, Elvira Padua ${ }^{1}$, \\ David Della-Morte ${ }^{3,4}$, Massimiliano Caprio ${ }^{1,5}$ and Alfonso Bellia ${ }^{4}$
}

1 Department of Human Sciences and Promotion of the Quality of Life, San Raffaele Open University, Via di Val Cannuta, 247, 00166 Rome, Italy

2 Institute of Clinical Biochemistry, Clinical Molecular Medicine and Laboratory Medicine, Department of Biomedicine, Neuroscience and Advanced Diagnostics, University of Palermo, Palermo, Italy

3 The Evelyn F. McKnight Brain Institute, Department of Neurology, Miller School of Medicine, University of Miami, Miami, FL 33136, USA

4 Department of Systems Medicine, University of Rome “Tor Vergata”, Rome, Italy

5 Laboratory of Cardiovascular Endocrinology, IRCCS San Raffaele Pisana, Rome, Italy

* Correspondence: mauro.lombardo@uniroma5.it

+ Presented at the 1st International Electronic Conference on Plant Science, 1-15 December 2020; Available online: https://iecps2020.sciforum.net/.

Published: 1 December 2020

\begin{abstract}
Introduction: Although some reviews demonstrated the advantages of a diet with a higher protein intake, other reviews have observed that a diet high in carbohydrates, with low-glycaemic index carbohydrates and good fibre intake, is equally effective in improving insulin sensitivity. The aim of this presentation is to show the ideal protein quality and quantity and the dietary composition for the prevention and metabolic control of type 2 diabetes mellitus (T2DM). Methods: Over 2831 articles were screened, and 24 from the last 5 years were analysed and summarised for this review, using the protein, diabetes and insulin glucose metabolic keywords in Pubmed in June 2019. Results: Eleven studies demonstrate that a higher consumption of proteins has a positive effect on insulin sensitivity. A higher intake of animal protein seems to be related to an increased risk of T2DM. Four studies show that consumption of meat has a deleterious effect. Higher intake of plant protein and dairy products is associated with a modestly reduced risk. Discussion: Based on the results obtained, for the prevention of T2DM and all disorders related to metabolic syndrome, no ideal dietary composition has yet been found. The advantage of plant protein sources may be related to the foods' low-glycaemic index due to the high fibre content. However, the right protein quality (animal and plant) and the quantity for T2DM prevention and metabolic control are unclear and need to be investigated with further long-term studies.
\end{abstract}

Keywords: type 2 diabetes; protein; plant; quality; intake; diet

\section{Introduction}

Mediterranean diet, with its recommendation to reduce protein from animal sources and to improve intake of whole grain carbohydrates and fibres, has been considered for decades the cornerstone for people with or at risk of T2DM [1] Fibre consumption, by regulating postprandial glucose and insulin levels, can be effective to improve metabolic control in people with T2DM and pre-diabetes [2-4].

There are conflicting views on protein intake. Some studies highlighted animal protein consumption as a factor predisposing to insulin resistance and T2DM, especially during intentional caloric restriction to induce weight loss [5], while others have reported that a moderately high 
consumption of proteins can improve IS and weight loss. Nevertheless, how protein dietary intake can actually affect glucose homeostasis, insulin signalling and risk of developing T2DM is not fully understood [6]

According to this background, we performed a narrative review of the major evidence from literature on the effects of dietary protein intake on glucose homeostasis and regulation in people with or at risk of T2DM.

\section{Materials and Methods}

We searched electronic databases of PubMed, Web of Science, EMBASE and Cochrane Central Register of Controlled Trials (CENTRAL) using the following keywords as title/abstract fields: ("insulin resistance" OR "insulin sensitivity" OR "type 2 diabetes" OR "diabetes" OR "T2DM") AND ("protein" OR "protein diet" OR high protein" OR "protein intake" OR "Protein OR “dietary protein" OR "“population" or "human").

Filtering the results of the last 5 years, 2831 studies with these characteristics were obtained. Two hundred eighty-nine papers were excluded because they were duplicate studies. Of these, an additional 2042 were excluded with use of the criteria above after title and abstract review, leaving 500 articles for full text review.

\section{Results}

Twenty-four studies (reviews/meta-analysis) are considered for this review [7-30]. Of the 24 articles we considered, 16 are studies on T2DM patients, 4 on obese patients and 7 assessed the risk of diabetes in healthy patients.

\section{Discussion}

It is controversial whether different dietary sources of protein can elicit different effects and therefore result as more preferable choices for patients with or at risk of T2DM. Some of thestudies evaluated $[16,17,30]$ did not distinguish the animal protein source (Table 1) but simply affirmed an increased risk given by an increased animal protein intake.

Table 1. Differences in insulin sensitivity for different protein sources.

\begin{tabular}{|c|c|c|c|c|c|c|}
\hline Study & Year & Meat & Fish & Eggs & Dairy products & Plant protein \\
\hline Liu AY. et al. & 2015 & & & & ++ & \\
\hline Pasin G. et al. & 2015 & & & & ++ & \\
\hline Malik VS et al. & 2016 & - - & $?$ & $?$ & $?$ & ++ \\
\hline Parackal S. & 2016 & - - & & & - & \\
\hline Jung CH. et al. & 2017 & -- & \pm & \pm & ++ & \\
\hline Tian S et al. & 2017 & & & & & ++ \\
\hline Geiker NRW. et al. & 2018 & & & \pm & & \\
\hline Zhao LG. et al. & 2019 & - - & $?$ & $?$ & $?$ & ++ \\
\hline
\end{tabular}

Table 2. Studies that report the nature of the protein component analysed. 


\begin{tabular}{|c|c|c|c|c|}
\hline Study & Year Population & Type (n) & Effects on IS* & Details of the study objectives \\
\hline Mignone LE et al. & 2015 T2DM & Different & ++ & Milk protein analysis (whey) for insulin sensitivity \\
\hline Pasin G et al. & 2015 T2DM & RCT (28) & ++ & Analysis of the effect of dairy protein on IR and T2DM people \\
\hline Vasanti S. Malik et al. & 2016 All & Cohort (3) & -. & Population studies. Association between different protein sources (animalsNegetals) and T2DM risk \\
\hline Parackal S. & 2016 All & Descriptive & -. & Population studies. Association of western eating habits and protein consumption with IR and T2DM \\
\hline Tian S et al. & 2017 T2DM & Cohort (11) & -. & Cohort studies. Associations between different protein sources (animals/vegetals) and T2DM risk. \\
\hline Geiker NRW et al. & 2018 T2DM & Osbser./ interv. (3) & $+1-$ & Analysis of interventionallobservational studies. Correlation between egg consumption and T2DM and CVD \\
\hline Zhao LG et al. & 2019 All & Cohort (8) & -- & Cohort studies. Associations between different protein sources (animals/vegetals) and T2DM risk. \\
\hline \multicolumn{5}{|c|}{$\begin{array}{l}\text { *Insulin sensitivity differences based on study conclusions: } \\
(++) \text { positive, better parameters than standard diets with high carbohydrates, proteins help insulin sensitivity } \\
(++-) \text { none, there are no differences between HP and HC diets, proteins do not affect insulin sensitivity } \\
(--) \text { negative, standard high carbohydrate diet has better outcomes on insulin sensitivity, proteins lower insulin sensitivity }\end{array}$} \\
\hline
\end{tabular}

Regarding the effect of animal protein on IR, only few studies evaluated animal protein intake from plant intake. Several studies show that excessive consumption of red meat could have negative effects in the long term. A high red meat consumption could negatively affect glucose/insulin homeostasis and inflammatory profile, via mechanisms involving central fat accumulation. [31]

Adding enough protein (20-25\%) especially from vegetable sources is suggested to be a diet prescription for the prevention and management of T2DM [25]. Thus, other studies suggest an increase in the consumption of plant protein (as legumes) which, due to the simultaneous presence of dietary fibre, would have positive effects on insulin sensitivity.

Accordingly, a recent meta-analysis of RCTs on the effects of replacing animal proteins with plant proteins on glycaemic control in subjects with T2DM [32,33] hypothesised various interestingmechanisms potentially leading to the improvement of IS observed with plant consumption. It has been observed that the intake of raw protein plant foods leads to more significant results than the integration with plant proteins in the improvement of various parameters of T2DM [34].

A review assessed whether dietary total, animal, and plant protein could be associated with type 2 diabetes risk. Total protein was associated with a higher risk of T2D and this association was largely due to the protein of animal origin. Plant protein had a modest nonlinear dose-response association with T2D risk. Therefore, public health recommendations should consider the protein sources for T2D prevention [30].

Iron heme consumption, which is much more bioavailable, appears to be associated with an increased risk of T2DM. In contrast, plants contain iron in the inorganic form (not heme), which is less bioavailable and ismore difficult to absorb. Another potential protection mechanism may be related to the different amino acid profiles of plant sources richer in L-arginine [35]. This aminoacid seems to be related to improving insulin sensitivity by promoting insulin secretion by pancreatic cells due to the effect on electrical activity. Nevertheless, the studies analysed are highly confusing, and the variations are too small to be considered reliable.

Recommendations from current guidelines in terms of adherence to healthy and varied dietetic habits, based on natural and hardly processed foods, alongside regular physical exercise, remain to be the cornerstone to effectively counteract the increasing epidemic of T2DM and related diseases.

Acknowledgments: This research received no specific grant from any funding agency in the public, commercial, or not-for-profit sectors.

Conflict of interest: The authors declare that they have no competing interests.

\section{References}

1. Esposito, K.; Maiorino, M.I.; Bellastella, G.; Panagiotakos, D.B.; Giugliano, D. Mediterranean diet for type 2 diabetes: Cardiometabolic benefits. Endocrine 2017, 56, 27-32, doi:10.1007/s12020-016-1018-2.

2. Shepherd, P.R.; Kahn, B.B. Glucose transporters and insulin action-Implications for insulin resistance and diabetes mellitus. N. Engl. J. Med. 1999, 341, 248-257.

3. Lattimer, J.M.; Haub, M.D. Effects of dietary fiber and its components on metabolic health. Nutrients 2010, 2, 1266-1289, doi:10.3390/nu2121266.

4. Neuenschwander, M.; Ballon, A.; Weber, K.S.; Norat, T.; Aune, D.; Schwingshackl, L.; Schlesinger, S. Role of diet in type 2 diabetes incidence: Umbrella review of meta-analyses of prospective observational studies. BMJ 2019, 3, 12368, doi:10.1136/bmj.12368.

5. Nita, F.; Anoop, M.; Viswanathan, M.; Roy, T.; William, Y. Dietary and nutritional approaches for prevention and management of type 2 diabetes. BMJ 2018, 361, k2234. 
6. Smith, G.I.; Yoshino, J.; Kelly, S.C.; Reeds, D.N.; Okunade, A.; Patterson, B.W.; Klein, S.; Mittendorfer, B. HighProtein Intake during Weight Loss Therapy Eliminates the Weight-Loss-Induced Improvement in Insulin Action in Obese Postmenopausal Women. Cell Rep. 2016, 17, 849-861, doi:10.1016/j.celrep.2016.09.047.

7. Ajala, O.; English, P.; Pinkney, J. Systematic review and meta-analysis of different dietary approaches to the management of type 2 diabetes. Am. J. Clin. Nutr. 2013, 97, 505-16.

8. Rietman, A.; Schwarz, J.; Tomé, D.; Kok, F.J.; Mensink, M. High dietary protein intake, reducing or eliciting insulin resistance? Eur. J. Clin. Nutr. 2014, 68, 973-9.

9. Liebman, M. When and why carbohydrate restriction can be a viable option. Nutrition 2014, 30, 748-54.

10. Hernández, A.G.; Jiménez, C.A.; Bacardí, G.M. Effect of low carbohydrate diets on weight loss and glycosilated hemoglobin in people with type 2 diabetes: Systematic review. Nutr. Hosp. 2015, 32, 1960-6.

11. Liu, A.Y.; Silvestre, M.P.; Poppitt, S.D. Prevention of type 2 diabetes through lifestyle modification: Is there a role for higher-protein diets? Adv. Nutr. 2015, 13, 665-73.

12. Mignone, L.E.; Wu, T.; Horowitz, M.; Rayner, C.K. Whey protein: The "whey" forward for treatment of type 2 diabetes? World J. Diabetes 2015, 25, 1274-84.

13. Campbell, A.P.; Rains, T.M. Dietary protein is important in the practical management of prediabetes and type 2 diabetes. J. Nutr. 2015, 145, 164S-169S.

14. Pasin, G.; Comerford, K.B. Dairy foods and dairy proteins in the management of type 2 diabetes: A systematic review of the clinical evidence. Adv. Nutr. 2015, 15, 245-59.

15. van Wyk, H.J.; Davis, R.E.; Davies, J.S. A critical review of low-carbohydrate diets in people with Type 2 diabetes. Diabetes Med. 2016, 33, 148-57.

16. Gow, M.L. The Effectiveness of Different Diet Strategies to Reduce Type 2 Diabetes Risk in Youth. Nutrients 2016, 8, 486 .

17. Steckhan, N.; Hohmann, C.D.; Kessler, C.; Dobos, G.; Michalsen, A.; Cramer, H. Effects of different dietary approaches on inflammatory markers in patients with metabolic syndrome: A systematic review and metaanalysis. Nutrition 2016, 32, 338-48.

18. Comerford, K.B.; Pasin, G. Emerging Evidence for the Importance of Dietary Protein Source on Glucoregulatory Markers and Type 2 Diabetes: Different Effects of Dairy, Meat, Fish, Egg, and Plant Protein Foods. Nutrients 2016, 8, 446.

19. Malik, V.S.; Li, Y.; Tobias, D.K.; Pan, A.; Hu, F.B. Dietary Protein Intake and Risk of Type 2 Diabetes in US Men and Women. Am. J. Epidemiol. 2016, 183, 715-728.

20. Parackal, S. Dietary Transition in the South Asian Diaspora: Implications for Diabetes Prevention Strategies. Curr. Diabetes Rev. 2017, 13, 482-487.

21. Jung, C.H.; Choi, K.M. Impact of High-Carbohydrate Diet on Metabolic Parameters in Patients with Type 2 Diabetes. Nutrients 2017, 9, 322.

22. Yamada, S. Paradigm Shifts in Nutrition Therapy for Type 2 Diabetes. Keio J. Med. 2017, 66, $33-43$.

23. Tian, S.; Xu, Q.; Jiang, R.; Han, T.; Sun, C.; Na, L. Dietary Protein Consumption and the Risk of Type 2 Diabetes: A Systematic Review and Meta-Analysis of Cohort Studies. Nutrients 2017, 9, 982.

24. Gershuni, V.M.; Yan, S.L.; Medici, V. Nutritional Ketosis for Weight Management and Reversal of Metabolic Syndrome. Curr. Nutr. Rep. 2018, 7, 97-106.

25. Mohan, V.; Unnikrishnan, R.; Shobana, S.; Malavika, M.; Anjana, R.M.; Sudha, V. Are excess carbohydrates the main link to diabetes \& its complications in Asians. Indian J. Med. Res. 2018, 148, 531-538.

26. Guess, N.D. Dietary Interventions for the Prevention of Type 2 Diabetes in High-Risk Groups: Current State of Evidence and Future Research Needs. Nutrients 2018, 10, 1245.

27. Zhao, W.T.; Luo, Y.; Zhang, Y.; Zhou, Y.; Zhao, T.T. High protein diet is of benefit for patients with type 2 diabetes: An updated meta-analysis. Medicine (Baltim.) 2018, 97, e13149.

28. Drummen, M.; Tischmann, L.; Gatta-Cherifi, B.; Adam, T.; Westerterp-Plantenga, M. Dietary Protein and Energy Balance in Relation to Obesity and Co-morbidities. Front. Endocrinol. (Lausanne) 2018, 9, 443.

29. Geiker, N.R.W.; Larsen, M.L.; Dyerberg, J.; Stender, S.; Astrup, A. Egg consumption, cardiovascular diseases and type 2 diabetes. Eur. J. Clin. Nutr. 2018, 72, 44-56.

30. Zhao, L.G.; Zhang, Q.L.; Liu, X.L.; Wu, H.; Zheng, J.L.; Xiang, Y.B. Dietary protein intake and risk of type 2 diabetes: A dose-response metaanalysis of prospective studies. Eur. J. Nutr. 2019, 58, 1351-1367.

31. Mazidi, M.; Kengne, A.P.; George, E.S.; Siervo, M. The Association of Red Meat Intake with Inflammation and Circulating Intermediate Biomarkers of Type 2 Diabetes Is Mediated by Central Adiposity. Br. J. Nutr. 2019, 1-20, doi:10.1017/S0007114519002149. 
32. Chalvon-Demersay, T.; Azzout-Marniche, D.; Arfsten, J.; Egli, L.; Gaudichon, C.; Karagounis, L.G.; Tomé, D. A Systematic Review of the effects of plant compared with Animal Protein Sources on Features of Metabolic Syndrome. J. Nutr. 2017, 147, 281-292.

33. Abril-Ulloa, V.; Flores-Mateo, G.; Solà-Alberich, R.; Manuel-y-Keenoy, B.; Arija, V. Ferritin levels and risk of metabolic syndrome: Meta-analysis of observational studies. BMC Public Health 2014, 14, 483, doi:10.1186/1471-2458-14-483.

34. Rosenzweig, J.L.; Bakris, G.L.; Berglund, L.F.; Hivert, M.; Horton, E.S.; Kalyani, R.R.; Murad, M.H.; Vergès, B.L. Primary Prevention of ASCVD and T2DM in Patients at Metabolic Risk: An Endocrine Society Clinical Practice Guideline. J. Clin. Endocrinol. Metab. 2019, doi:10.1210/jc.2019-01338.

35. Te Morenga, L. The effect of a diet moderately high in protein and fiber on insulin sensitivity measured using the dynamic insulin sensitivity and secretion test (DISST). Nutrients 2017, 9, E1291.

Publisher's Note: MDPI stays neutral with regard to jurisdictional claims in published maps and institutional affiliations

(C) 2020 by the authors. Submitted for possible open access publication under the terms and conditions of the Creative Commons Attribution (CC BY) license (http://creativecommons.org/licenses/by/4.0/). 